УДК 004

http://doi.org/10.36906/KSP-2020/57

Платонова Н.А.

Нефтеюганский политехнический колледж

г. Нефтеюганск, Россия

\title{
ИСПОЛЬЗОВАНИЕ ПРОГРАММЫ МЕNТIМЕТЕR НА УРОКАХ ОБЩЕГУМАНИТАРНЫХ ДИСЦИПЛИН
}

Аннотация. Преподаватели организуют свои уроки не только с целью дать знания, они хотят создать процесс получения учебного материала более интересным для обучающихся. Это необходимо для того, чтобы все участники урока из пассивной позиции перешли в активную. Достигнуть данного эффекта не всегда просто, многим трудно давать ответы устно, а тесты и письменные опросы уже не представляют такого интереса, как раньше. Поэтому преподаватели изучают и реализуют на своих уроках программы, которые могут помочь им достигнуть заинтересованности своих студентов. Одной из таких программ является Mentimeter. Один из главных плюсов данной программы заключается не в запрете использования гаджетов на уроках, a, наоборот, их привлечении.

Ключевые слова: гаджеты; программа; Mentimeter.

С каждым днем все тяжелее сохранять интерес обучающихся к предмету. В школе обучающиеся акцентируют свое внимание на дисциплинах, которые планируют сдавать в качестве экзамена, в СПО обучающиеся заинтересованы в дисциплинах профессионального цикла, в результате, к сожалению, к предметам общеобразовательного цикла интерес небольшой. Обучающиеся приходят на занятия, чтобы заработать оценку, а не знания. Если преподаватель своим уроком не вызывает интереса у студентов, значит свое внимание они будут уделять гаджетам. Можно сказать, что каждый современный преподаватель «ведет неравный бой с гаджетами». Но из этой непростой, на первый взгляд, ситуации можно найти выход. Не нужно враждовать с гаджетами, нужно сотрудничать с ними, и тогда мы получим интерес со стороны детей, а значит сохраним внимание.

Способов для достижения такой цели, как завоевание интереса к предмету со стороны обучающихся, множество. Нужно только подобрать их под себя, под свой предмет и, конечно, под свою аудиторию. Например, одной из очень удобных программ является Mentimeter. Mentimeter - это простой, удобный и доступный способ, обеспечивающий проведение опросов. Одним из главных его плюсов является получение мгновенной обратной связи от аудитории. Его удобно использовать в вузах и СПО, ведь программа позволяет опросить студентов в режиме реального времени, а доступен он на всех мобильных устройствах. Главное условие - доступ в Интернет. Нельзя оспорить тот факт, что тесты достаточно полно вошли в образовательный процесс, у них есть доброжелатели и недруги. Но одно остается неизменным: мы не можем представить себе образовательный процесс без них. Большая часть обучающихся привыкли к бумажным носителям, иногда им 
даже не хочется думать и тогда они могут дать ответ наугад, иногда, при отсутствии желания мыслить, начинают искать ответы в Интернете с помощью своих гаджетов. Преподаватели, в свою очередь, просят отказаться от телефонов во время ответов. Mentimeter позволит не только привлечь внимание и погрузить каждого в образовательный процесс, но и в результате такой работы не возникнет желания найти ответ, захочется дать его самостоятельно. К сожалению, современное общество с раннего детства взаимодействует с телефонами, и поэтому подростки не могут себе представить минуту своего времени без Интернета. Использование гаджетов на уроках позволяет не тратить время на замечания и в то же время получить объективную оценку знаний по пройденной теме.

Использовать Mentimeter на уроках не только удобно, но и ффективно. Преподаватель заранее создает опрос, вопросы могут быть разные. Открытые или с выбором ответов, также можно дополнить вопрос иллюстрацией. На уроке преподаватель запускает опрос с ПК. На экране отображается адрес и код опроса для студентов. Программой можно пользоваться не только через приложение, можно пройти опрос через встроенный браузер. Студенты, используя свои гаджеты, входят на сайт www.menti.com, вводят код опроса и отвечают на вопрос(ы). На экране мгновенно отображаются результаты опроса. Проводить опрос можно как в синхронном режиме (в аудитории, «здесь и сейчас»), так и в асинхронном - в любое время в пределах заданного интервала опроса.

Программа Mentimeter на первый взгляд не создает впечатления, что может помочь в образовательной сфере. Действительно, изначально программа была создана для бизнеса, основная задача была презентовать продукт и проводить опросы, главный плюс заключался в получении мгновенного результата. Сейчас его можно активно использовать в образовании, так как он позволяет создать презентацию, в рамках которой можно провести опрос или викторину.

На сайте создаем свою презентацию, включаем в нее вопросы для опроса обучающихся. У нас есть выбор слайдов. Можно выбрать открытый вопрос и установить время, которое дано обучающимся для ответа на вопрос, так как они должны набрать на своих гаджетах ответ.

Викторины удобны тем, что они формируют рейтинг, определяется победитель. Викторина оценивает не только правильный ответ на вопрос, но и быстроту ответа. Викторину можно проводить не только среди подгрупп обучающихся, но и среди общей группы.

На наш взгляд, главным плюсом программы Mentimeter является мгновенная оценка того, как хорошо обучающиеся поняли тему, сразу можно обсудить правильные ответы и разобрать ошибки.

Программа позволяет использовать изображения, поэтому создание презентации не требует большого количества времени. Можно использовать имеющиеся презентации, просто сохранять каждый слайд как картинку.

Обучающимся интересно использовать обозначения, которые есть в программе. Допустим, у обучающихся возник вопрос, они могут использовать этот значок. Преподаватель сразу видит, какое количество обучающихся не поняли материал. Можно использовать сердечко, которое дает возможность положительно оценить задание, предложенное преподавателем. 
Главный минус программы заключается не в трудности ее реализации, а в том, что в платной версии больше возможностей. На бесплатной основе можно использовать пять форм для создания тестов и три формы для интерактивной работы, а в платной версии, естественно, возможностей больше.

Приведем один из интереснейших опытов использования Mentimeter на уроке литературы. Тема урока была связана с творчеством М.А. Булгакова «Любовь и судьба Мастера». Урок по теме был не первый, поэтому содержание романа $80 \%$ обучающихся уже знали. Необходимо было узнать, насколько материал является освоенным, в каком направлении нужно двигаться, на что следует сделать акценты. В данном случае было решено провести опрос, он содержал не только вопросы с выбором ответа, но и открытые. Тем самым удалось активизировать деятельность студентов, заинтересовать их. Опрос был включен в этап урока под названием «Актуализация опорных знаний». Времени было затрачено немного, 5-7 минут. Но именно этот этап «встряхнул» обучающихся и всех привлек к образовательному процессу.

Подведем итог. Особенности Mentimeter заключаются в следующем:

- можно использовать готовые шаблоны или использовать свою презентацию;

- нет необходимости скачивать приложение на телефон;

- сервис обеспечивает мгновенной обратной связью с каждым обучающимся. Можно установить время выполнения теста целиком или ответа на конкретный вопрос.

- работа с сервисом не представляет трудностей, обучающиеся вставляют в поисковую строку браузера ссылку govote.at и код опроса, а могут сканировать QR-код, который показан на экране;

- гаджеты отображают ряд цветных вариантов ответов на поставленный вопрос;

- вопросы могут содержать не только выбор ответа, но и открытый вопрос;

- оценивание происходит по оценочной шкале;

- ранжирование ответов в пределах $100 \%$.

Хочется того или нет, но современному преподавателю необходимо быть в курсе всех технологий, которые могли бы привлечь обучающихся в образовательный процесс. Конечно, на все это необходимо тратить немалое количество времени, но не стоит забывать, что основная задача преподавателя - не только дать знания, но и направить на путь получения информации. Mentimeter позволяет это осуществить. Наш опыт позволяет сделать такие выводы, поскольку если до опроса больше половины группы не хотели знакомиться с текстом, то после тестирования данное желание появилось у всех. Многие просто увидели другую возможность проведения урока. Иная форма проверки знаний позволила традиционный формат превратить в актуальный для современного поколения с помощью гаджетов. Тем более данный сервис можно применять на любых уроках, как на гуманитарных, так и на естественно-научных.

На сегодняшний день в связи с непростой ситуацией является актуальным дистанционное обучение, но программа не рассчитана только на очное взаимодействие с обучающимися. Систему также можно использовать и в офлайн-режиме. Например, во время проведения уроков в Zoom. Поэтому не стоит использовать программу только в узкой направленности. Интересно использовать программу в рамках студенческих конференций. У нас ежегодно проводится конкурс научно-исследовательских работ, выступающие в конце 
своего выступления могут предложить опрос в Mentimeter. В данной ситуации он позволит получить мгновенную обратную реакцию от аудитории. Процесс проведения конференции перейдет из пассивного участия в активное. Стоит учитывать и психологию участников конференции. Многим тяжело сформулировать свои мысли, осмелиться задать свой вопрос. Поэтому опрос в Mentimeter позволяет избежать стрессовых ситуаций. Можно воспользоваться анонимным голосованием, оно позволит получить информацию об общем уровне понимания темы. Участники не будут бояться открыто выразить личное мнение, тем самым предоставляется возможность уйти от стереотипного мышления. В таком формате отсутствует критика, нет отрицательной оценки со стороны окружающих. Результат будет не только точным, но и объективным, так как участники не увидят давления со стороны окружающих. Анонимность позволяет избежать доминирования со стороны лидеров.

Mentimeter может помочь решить множество задач. У каждого свои интересы для привлечения в работу данной программы. Кто-то хочет провести открытый урок по Федеральному государственному образовательному стандарту. Кто-то находится на дистанционном обучении. Возможно, нужно провести мастер-класс для преподавателей.

Mentimeter может решить все эти цели, потому что при выборе онлайн-сервиса мы руководствуемся тремя основными критериями:

- Простой и понятный интерфейс - это дает возможность потратить меньше времени;

- Возможность пройти опрос без регистрации;

- Полифункциональность позволяет использовать ресурс на любом этапе урока [2].

Опросы в Mentimeter преподаватель может давать на уроке при проверке домашнего задания, в качестве актуализации опорных знаний, на этапе первичной проверки понимания нового материала, в середине занятия в качестве инструмента для зондирования проблемных мест, в конце урока на этапе рефлексии. Можно поручить обучающимся самостоятельно подготовить опросы в программе для своих одногруппников. Ведь непросто сформулировать вопросы. И, конечно, выполнение таких заданий не только активизирует аудиторию, вовлекает всех в учебный процесс, но и вызывает положительные эмоции.

Исходя из своего опыта использования программы, Mentimeter удобно использовать с пользой в пяти основных случаях:

1. Изучение нового материала, например, лекция. Изначально можно собрать мнение аудитории о теме, формулировке задач урока. Что они ожидают? Какие цели перед собой ставят?

2. Урок-диалог, который предполагает ответы аудитории на вопросы-ловушки, комментарии. Вопросы могут быть разные, требующие односложных ответов (да - нет, согласен - не согласен), также можно предложить голосование за лучший ответ.

3. Включение в урок креативных заданий. Формат вордклауда, например, предполагает ответ на вопрос с помощью одного слова: Каким одним словом можно описать главного героя? Количество вопросов лучше настроить до презентации. Вопросы зависят от дисциплины. С обучающимися все ответы на вопросы можно визуализировать и собрать все варианты от каждой группы.

4. Для моментальных квизов и контроля знаний. Это могут быть вопросы по уже известной теме, актуализация знаний. Есть возможность задать вопросы на смекалку, опрос в качестве разминки на уроке. 


\section{КУЛЬТУРА. НАУКА. ОБРАЗОВАНИЕ}

5. Рефлексии в конце занятия. Во-первых, позволяет определить эмоции обучающихся после урока. Во-вторых, поможет нам как преподавателям обратить внимание на проблемы, которые появились во время изучения темы, и отработать трудные моменты.

Презентации мы включаем в каждый урок, а вот интерактивные презентации звучат поновому и вызывают интерес. Все, что мы слышим впервые, вызывает у каждого из нас особый интерес, хочется попробовать, тем более, когда наших обучающихся очень трудно удивить. Посредством Mentimeter можно превратить выступление в диалог с аудиторией. В этот период группа из пассивных слушателей превратится в активных участников урока. Удобство заключается в том, что выступающий может чередовать слайды для показа и слайды для взаимодействия, проводя опросы, собирая мнения, организуя голосования.

Преподаватель вне зависимости от своего возраста должен идти в ногу со временем, чтобы это осуществить, мы должны следовать за трендами технологий. На самом деле это несложно, потому что технологии находятся от на расстоянии вытянутой руки.

СПлатонова Н.А., 2020 